\title{
The good doctor
}

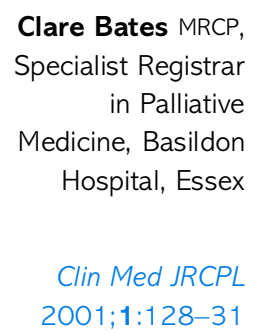

Clare Bates MRCP, Specialist Registrar in Palliative

Medicine, Basildon Hospital, Essex

Clin Med JRCPL 2001;1:128-31

This article is based on the proceedings of a conference entitled

The Interface between doctors, patients and patient support groups held at the Royal College of Physicians on 27 September 2000

\section{Claire Bates}

Give me a doctor partridge plump,

Short in the leg and broad in the rump,

An endomorph with gentle hands

Who never makes absurd demands

That I abandon all my vices,

Nor pulls a long face in a crisis,

But with a twinkle in his eye

Will tell me that I have to die.

(W H Auden)

Read this to an audience attending a conference on doctor-patient relationships at the beginning of the 21 st century and there will be knowing smiles; the doctor-patient relationship Auden describes is as dated as the language he employs. The paternalism of ancient and modern history is being replaced by the doctor-patient partnership for the new millennium.

Give me a doctor underweight, Computerised and up to date,

A businessman who understands Accountancy and target bands, Who demonstrates sincere devotion To audit and to health promotion, But when my outlook's for the worse Refers me to the practice nurse.

\section{(Marie Campkin)}

Is this what patients want from the medical profession in the 21st century? Is the doctor-patient relationship really changing in consulting rooms and hospital wards up and down the country? If things are changing, is the change for the better? One way to find out is to invite patients and doctors to attend a conference on the subject, creating a forum for discussion and space to examine the interface between patients and their doctors. A conference that sets the modern doctor-patient relationship within its historical, ethical and sociological context, that examines the communication problems within the relationship and that listens to the voice of patients, as individuals and as spokespersons for the groups they represent. Twenty-three doctors attended this conference, comprising 19\% of conference delegates. So, for those thousands of doctors who did not attend, the following is a brief educational taste of what they missed.

\section{The current climate}

Hardly a week goes by without the media exposing the latest doctor failing in his/her duty to patients. Some doctors may feel that the media's portrayal of the medical profession invariably acts to inflame conflict between doctors and patients, and is strongly biased against doctors. Nick Ross, speaking as 'the media's voice' on this subject, firmly placed responsibility back with the public. The media exists to sell a product, so the consumer is the ultimate arbiter of the market place. Consumers use the media to massage opinions they already hold. If, then, 'doctor bashing' is in the air, the media will inflame the debate, and will do so with whatever constitutes 'a good story'.

\section{The historical/ethical perspective}

Hippocrates instructed the physician to conceal 'most things from the patient while attending him'. This policy was reinforced by 19 th century ethical guidelines for the profession which stated that the patient's right to truth 'is suspended, and even annihilated' if it would prove damaging to them, their family or the community ${ }^{1}$. This policy persisted well into the 20th century: in 1961 one study showed that $90 \%$ of doctors withheld a diagnosis of cancer from the patient ${ }^{2}$. Since then, however, a new code of medical ethics has been defined; the four principles of beneficence, non-maleficence, respect for patient autonomy and justice have transformed and reinforced the ethical foundation of the doctor-patient relationship.

The doctor's commitment to beneficence marks the doctor-patient relationship out as different from other relationships where neither are doctors. Few groups in society make a similar commitment and doctors' common ground in this respect is with groups such as firefighters or lifeboat crews. The spin-offs of this principle include continuing medical education, establishing and maintaining good standards of practice, commitment to research, obligation not to promote unnecessary treatments, the admission of mistakes and protection of patients from risk. On the latter, doctors have always been good at closing ranks when under attack, but the commitment to the patient's good 
should trump doctors' commitment to each other in such circumstances.

In respecting patient autonomy, the doctor's duty of care encompasses giving adequate information in a way that is understood, thus enabling the patient to make informed choices. This is best demonstrated with the issue of informed consent. Here the doctor's ability to communicate effectively is under scrutiny.

Respecting patient autonomy is about sharing information and so moving from paternalistic decision making to partnership. Some authors have proposed three ways that doctors consult with patients ${ }^{3}$. In the 'paternalistic' model, the doctor decides what to do. In the 'partnership' or 'shared' model, the doctor and patient decide together. In the third, the 'informed' or 'consumerist' model, the patient makes the decision on the basis of the information the doctor has provided. Some believe that the shared model is just a staging post on the road from the paternalistic to the informed model. Others have pinned their hopes for the salvation of the doctor-patient relationship on this shared model, believing that this is the way to improve outcomes, decrease costs, increase patient satisfaction and facilitate research.

Professor Raanan Gillon, speaking at the conference, suggested an alternative 'third model' - a battle between doctor and patient arising out of the patient's demand that the doctor comply with the patient's wishes. He sees this as a consequence of respect for patient autonomy in the extreme. In this hypothetical situation, he suggested the doctor will then shed the broader (often extra-contractual) professional commitment to the patient's good and enter into a defined contractual agreement based on the consumer philosophy. He warns that, should this occur, patients will be the ones that suffer.

Partners work together to achieve common goals. It is imperative, therefore, that doctors and patients work together to make the doctor-patient partnership work, avoiding the battle situation that might ensue should the pendulum swing too far in the other direction from the paternalism of centuries past.

\section{The sociological perspective}

The sociological backdrop against which the doctor-patient relationship is played out is changing too. Sociologists now describe the emergence of the 'health role', as opposed to the 'sick role'. This has to do with the development of 'lay knowledge' as people are encouraged to inspect and understand their bodies. Increasingly, those with certain chronic illnesses learn selfmanagement of their condition. The internet has broadened access to health information further. Patients now come to their doctor with some knowledge and, in certain cases, as 'experts'. The patient expects to use this knowledge to ask questions. (This is reflected in the Department of Health's 'Patients as Experts' initiative.) Paternalistic decision making is out of step with other currents in modern society; disagreements can be acknowledged, conflict need not be avoided and experts can now be questioned, The changing doctor-patient interface reflects a changing society in the wider perspective.

\section{Doctors and patients: communication or dislocation?}

Is it true that a relationship is only as good as its communication? As the doctor-patient relationship is moving towards partnership, the new emphasis is on shared information, shared evaluation, shared decision making and shared responsibilities ${ }^{4}$. Obviously, this will only be achieved within the average eight minute general practice consultation, for example, if communication between the two parties is of a consistently high standard. There are also other compelling reasons to improve communication: according to various studies on drug compliance $20 \%$ of renal transplant patients did not take their prescribed drugs, only $13 \%$ of diabetic patients took two hypoglycaemic drugs properly, $33 \%$ taking one drug as prescribed ${ }^{5}$. Non-compliance with prescribed treatment/advice or misunderstanding between the doctor and patient is the norm, not the exception.

This problem has been addressed in part by including communication skills training in the curriculum of most, if not all medical schools in the UK. While the standard of this teaching is improving, it is still the case that 'doctors to be' enter medical school 'dripping with empathy' and emerge after house jobs with poor communication skills, quite transformed by their journey to full registration. In his presentation to the conference, Dr Peter Tate describes vocational communication skills training of GP registrars as mainly 'remedial': trying to undo ingrained bad habits. Examining students/doctors on a given topic inevitably moves that topic up the learning agenda. The MRCGP examination attempts to underline the importance of good communication by examining candidates on video consultations, marked according to identified performance criteria.

Results presented at this conference from the last two years of video examinations (2,096 doctors performing 14,852 consultations) show that, while doctors do well in encouraging patients, establishing rapport, diagnosing, explaining, managing and prescribing, they do less well in finding out about the patient's psychological and social circumstances and picking up on verbal and non-verbal cues. Interestingly, their performance is even worse when it comes to sharing management options, seeking the patient's health beliefs and using these beliefs in the explanation. Only $8 \%$ of doctors demonstrated this behaviour. Finally, the results show doctors are poor at checking that the patient understands; fewer than $4 \%$ demonstrated such behaviour in more than one out of seven videotaped consultations.

General practice registrars also report not being trained in the skills required to involve patients in shared decision making ${ }^{6}$. The MRCGP data suggest that only about $10 \%$ do it well on observed videotaped consultations. The obvious conclusion from this is that it must be hard to do, although answers as to why it is so hard are speculative. In the partnership model of shared decision making, the doctor commits him/herself to an interactive relationship with the patient. This is a relationship where each brings their own expertise and where each relates to the other on the basis of their shared humanity rather than the imposed hierarchy of the paternalistic model. This behaviour 
does not come naturally to most doctors. It is hard to find the right balance between shared humanity and professional boundaries and there may be an emotional price to pay for a shift in emphasis. Furthermore, doctors find it difficult to disclose to patients the uncertainty that surrounds many treatment decisions. The patients themselves can sometimes be the most significant obstacles to the evolving doctor-patient partnership. Some patients want a paternalistic relationship. Others desire partnership but seem not to have understood the unspoken 'rules of the game'; hardly surprising when, unlike the doctor, the average patient is most unlikely to have received any training in communication to make the most of their eight minute consultation. This presents a further challenge to the doctor whose communication skills must also stretch to determining which patients want to be offered choice and which prefer a more passive role. Either way, it is clear that there is much room for improvement. If partnership is going to work, there will certainly be the need for more effective training in communication skills and better access to good quality information to support decision making. Perhaps the time has also come to teach patients how to communicate their agenda and make the most of the time available with their doctor ${ }^{7}$.

\section{The patient's voice and the role of self-help groups}

Joyce Robins, Director of Patient Concern, acknowledges that the blind trust patients placed in their physicians through centuries past has now disappeared. She stresses, however, that most of the public are pleased with their doctors, and that only a minority is committed to 'doctor bashing. While most patients do want partnership, she drew attention to the intrinsic vulnerability of the patient within the relationship and the difficulty this poses to an egalitarian approach. Even in the current accepted vocabulary, words like 'patient', 'managing' and 'obtaining consent' are not words of partnership but words implying hierarchy. Infrequently the focus of a patient's complaint is the practical problems of the relationship: the failure of the system, the operations postponed, the hours waiting to see a doctor and so on. Frequently, the core of the complaint is that the doctor failed to respect the patient as a fellow human being.

While engaged in the struggle to make their voice heard and be understood within the doctor-patient relationship, patients have increasingly found support and understanding within organised groups of other patients. These self-help groups (SHGs) are usually composed of members who, sharing a common difficult experience, voluntarily attend because they benefit from the group's existence and activities. Most members of such groups describe the relief of finding that they are 'not alone' ${ }^{8}$. For many, the group provides a 'safe' environment; a place to talk and be listened to, to struggle and be encouraged, to be vulnerable and considered important, ultimately to learn and to grow. Within an SHG there is equality and humanity; personal experience matters. Of course, the role of SHGs does not end there. Many provide leaflets, newsletters, telephone help-lines and educational material for professionals. Some also run befriending schemes, organise conferences and support clinical research financially. Several umbrella organisations exist to support smaller member organisations, campaign and influence policy and pioneer new ways of working. The Long-term Medical Condition Alliance, and Cancerlink, are good examples of these larger organisations.

Many doctors are unaware of the sheer number and importance of these patient-led groups. Others undoubtedly are unconvinced of the benefits and sceptical of the groups' motives. While some cynicism may have been justified in the past, many of the groups now follow good practice guidelines and recognise the need to work in partnership with, rather than against, the professionals. Some organisations, eg Diabetes UK, have professional as well as lay members. Furthermore, there is growing evidence for the effectiveness of group psychological therapies in improving patients' quality of life. Doctors ignore this evidence to the detriment of their patients' health.

Patients, or so-called 'lay people', have long had a voice within the health service as members of governance bodies and other committees. It is only recently, however, that they have been involved in doctor-patient groups discussing issues such as audit, standards, guidelines and revalidation ${ }^{9}$. At a local level, members of SHGs meet with professionals to discuss local issues. At a national level, the patient liaison groups of the Royal Colleges have facilitated decision making on difficult issues at the heart of professional practice and performance. The patient's voice heard in discussion at this level can change the way doctors view things and ensure that patient interests are always represented and protected.

\section{Conclusion}

The doctor-patient relationship is changing. The journey from paternalism to partnership is under way and, although there is still some distance to go, many doctors have, at least, set off on the road. A number will never start walking. They are the ones who would be most unlikely to attend a conference examining the interface between patients and their doctors (and perhaps unlikely to read to the end of the conference report). Those attempting the journey will need training, resources, support and encouragement if the final destination is to be reached. Already there are examples of doctors and patients coming together in organised partnership to help the profession improve standards of patient care. Meanwhile, doctors should not underestimate the therapeutic potential or resources available in the form of organised groups where patients talk to each other. As with any serious relationship, both parties must be committed to make the relationship work. There must be good communication, sharing of information, mutual respect and understanding. This means working through the difficulties and learning together.

\section{References}

1 Percival T. Medical ethics, 3rd edn. Oxford: John Henry Parker, 1849:140. 
2 Oken D. What to tell cancer patients: a study of medical attitudes. JAMA 1961;175:1120-8.

3 Charles C, Whelan T, Gatni A. What do we mean by partnership in making decisions about treatment? Br Med J 1999; 319:780-2.

4 Coulter A. Paternalism or partnership. (Editorial) Br Med J 1999; 319:719-20.

5 Morris A. Adherence to diabetic drug regimes. A study of 1060 patients by Dundee University. Data presented at British Diabetic Foundation Conference, April 2000.

6 Elwyn G, Edwards A, Gwyn R, Grol R. Towards a feasible model for shared decision making: focus group study with general practice registrars. Br Med J 1999;319:753-6.
7 Towle A, Godolphin W. Framework for teaching and learning shared decision making. Br Med J 1999;319:766-9.

8 Watts E. Self Help Groups: a personal and professional view. Eur J Cancer 2000;36:1340.

9 Williamson C. The challenge of lay partnership. (Editorial) $\mathrm{Br}$ Med J 1999;319:721-2.

Address for correspondence: Dr C Bates, St Joseph's Hospice, Mare Street, London E8 4SA. E-mail: clairebates@doctors.net.uk

\section{Principles of pain control in palliative care for adults}

This clear and succinct outline on pain control has been prepared for clinicians who look after terminally ill patients by a working group of the RCP Committee on Ethical Issues in Medicine. Although palliative care is now widely available, and there are many textbooks on the subject, some patients continue needlessly to suffer pain. Moreover, clinicians are concerned that the treatment they are delivering relieves pain effectively without shortening life.

The guidance covers

- caring for the dying patient and when to talk about dying

I matching the drugs to the patient's pain

I using morphine before the very last days of life

I what to do if the morphine is not working

I how best to administer the drugs - orally or intravenously

I when to seek help from a specialist team

The guideline is presented in an easy-to-read, 6-sided A4 fold-out for easy reference on wards and other settings where palliative care is offered.

\section{AVAILABLE FROM THE ROYAL COLLEGE OF PHYSICIANS}

Available in packs of 5 ISBN 1860161014

Price: UK $£ 10.00$, overseas $£ 12.00$ (prices include postage and packing) 